and whose intensity of scintillation is far smaller than that of the other three. With regard to the effect of the star's own colour it must be remarked that the relative frequency of that colour or of a nearly related one is often very great; thus, for instance, yellow is very frequent in the yellow star a Hydra, and orange in the orange stars Betelgeuze and $a$ Herculis. The total number of observations M. Montigny made of these six stars was 574 .

For the sake of comparison M. Montigny has calculated the relative frequency of colours in two stars of the second type, to which, as our readers will remember, our own sun belongs too. The stars selected were Pollux, with a very characteristic spectrum, and Capella, which scintillates with great regularity. Both stars are yellow and their spectra show very thin dark lines. The average frequency of colours for these two stars is given separately, $\mathbf{A}$ in rainy weather, and $\mathbf{B}$ in dry weather, from a total number of 267 observations of Capella and 116 observations of Pollux.

\begin{tabular}{|c|c|c|c|c|c|c|c|c|c|}
\hline & & ity. & Red. & Orange. & Yellow. & Green. & $\begin{array}{c}\text { Geenush } \\
\text { blue. }\end{array}$ & Blue. & Violet \\
\hline & $\ldots$ & 88 & 281 & 88 & 280 & 86 & 7 & $25^{\circ}$ & 8 \\
\hline & $\cdots$ & 63 & 299 & $4 I$ & 304 & 122 & 26 & 194 & 14 \\
\hline \multicolumn{3}{|c|}{ 1 verage 76} & 29 & 65 & 292 & 104 & 17 & 222 & II \\
\hline
\end{tabular}

If we compare these results with the former ones we find the frequency of red and particularly that of yellow to be consider. ably greater in Capelia and Pollux than in stars of the third type, while the frequency of orange is very much less, having decreased from 204 to 65 . The influence of the weather was equally appa. rent in these stars; in dry weather red was more frequent, and in rainy weather blue. The relative values of green and violet are greater in these two stars than in the fifteen stars of the third type; probably these colours will become more important when the observations are extended in a larger measure to the stars of the two first types.

It is therefore proved beyond doubt, by the results above mentioned, that the changes of colour which characterise the scintillation of stars, are subject to general laws which are quite as regular and fixed as those which govern the changes in the intensity of the phenomenon as we pass from one type to another, or under the influence of rain and fine weather.

In one of the last numbers of the Bulletin of the Brussels Royal Academy of Sciences M. Montigny publishes the results of some researches concerning the influence of the aurora borealis on the scintillation of stars. We may return to this subject at a future date.

\section{NOTES FROM NEW ZEALAND}

MR. T. H. POTTS, of Ohinitahi, N.Z., sends us the following notes :-

Which Species of Pinus have Cones really Sessile?-In working up the habits of a collection of pines one has felt a difficulty in understanding why certain cones should be termed sessile; for example, the cone of $P$. tuberculata is described by Gordon in his "Pinetum ;" also by Broun, in his "Forester," as "quite sessile." Why? Can such a description be correct at its early stage of life? It is then perched on a scaly foot-stalk, well developed; months elapse, its increasing bulk is protected with needle-pointed scales, its foot-stalk becomes curved, but is plainly visible; the mature cone, grey and glossy, clings tightly to its stem, it can scarcely be removed therefrom without tearing off a shell of bark adhering to the nasal scales; when wrenched off it shows a portion of its curved foot-stalk that has been embedded in the growing stem.

A very similar habit may be observed in $P$. insignis. Should not the cones of $P$. tuberculata and those of oiher species showing a similar habit, be described rather as apparently sessile than as "quite sessile"?

It may be mentioned that here $P$. tuberculata bears cones not only on the stem and main branches, but also on the soft green shoots of the outer branches, this would in part account for the foot-stalks becoming embedded in the growing bulk of the shoot.

$P$. insignis here bears cones of longer dimensions than those given by the authors before named; five specimens measure rather over seven inches in length, with a circumference of eleven inches.

Heredity.-One of my sons returning from a visit to the Chatham Isies, brought back with him a young pip of a famous colly breed. As soon as it was grown enough to run about it displayed an unusual excitement in the presence of horses by jumping upwards repeatedly towards their heads. As this trick or vice was unknown or unpractised by any of our dogs, it was, of course, soon remarked. On inquiry of a Chatham Island settler, I found this was a common trick in the colly family "Bell" sprang from; so Bell faithfully held to the habits of her race.

\section{UNIVERSITY AND EDUCATIONAL \\ INTELLIGENCE}

THE following programme of the Natural Science Courses in Trinity College, Dublin, may be of interest to our readers :In the Junior Sophister year natural science is represented by two courses-one in zoology, the other in botany. Students attending a course of lectures in natural science are examined three times during the term on the subjects of the lectures, and no student is allowed credit for his attendance who does not answer sufficiently. In the Senior Sophister year natural science is represented by one course in geology. In each term. examinations are held of those students in the Junior and Senior Sophister classes who are qualified to become candidates for honours. At the Michaelmas examination in the Junior Sophister year prizes of $4 \%$. and of $2 l$. are awarded by the Board, on the recommendation of the Honour Examiners, to the best answerers among the candidates. At the Hilary and Trinity examinations of the Junior and Senior Sophister years honours without prizes are awarded - of which honours there are two ranks. At the Michaelmas examination of the Senior Sophister year, examinations for Moderatorships are held. The Senior Moderators receive gold medals, and the Junior Moderators silver medals, which are given to them publicly before the University, by the Chancellor, at the commencements, when they are admitted to their degrees. The First Senior Moderator receives a large gold medal if specially recommended by the Court of Examiners. The subjects of examination for the Moderatorships in natural science are the following, each of which has equal weight :-I. Physical Geography, Geology, and Palæontology. All the ordinary and honour courses of the Sophister years. A limited course to be announced each year. Course for 1879 :- The Silurian Period. 2. General and Physiological Anatomy. A limited course to be announced each year. Course for I879:Circulation and Respiration. The Circulatory and Respiratory Organs in Mammals. The Respiration and Assimilation in PJants. 3. Zoology and Botany. All the ordinary and honour courses of the Sophister years. A limited course to be announced each year. Zoological Course for 1879:-The Non-Placental Mammals, Botanical Course for 1879:-The Fucoids, The Professors of Zoology, Botany, and Geology, give each a course of demonstrations and a course of lectures in each term, especially meant for Junior Sophisters. The Museum of Comparative Anatomy and Zoology is open, under the superintendence of the professor, to all students, to whom every facility is given for the prosecution of their studies. For the purposes of study fresh specimen of plants are, under the superintendence of the professor, to be had by the student from Mr. Frederick Moore, at the College Botanical Gardens, at Lansdowne Road; and large number of mounted specimens of cryptogamic plants are also to be seen and examined in the herbarium. The Museum of Geology and Palæontology is open to the students attending the course.

'THE Science and Art School of St. Thomas' Charterhouse Institution, Goswell Road (the largest in the United Kingdom) under the direction of the vice-chairman of the London School Board, commenced a new term on Monclay evening the 6th inst. Since the commencement of the present session upwards of 600 of our elementary school teachers of London have taken advantage of the privileges offered by the classes. The attendance at the classes for experimental work in chemistry and physics has been very large.

\section{SCIENTIFIC SERIALS}

Fournal of the Franklin Institute, November, 1878.-Some time ago Prof. Thurston invented apparatus for re-determining the coefficients of friction of lubricated surfaces, and the laws governing such friction, for a wide range of temperatures, pressures, and velocities. The machines have been in use about five 